\title{
A CULTURA POLÍTICA EM PORTO ALEGRE E CURITIBA: democracia, modernização e o conteúdo da razão pública*
}

\author{
Paulo J. Krischke**
}

\begin{abstract}
Resumo: Este estudo compara certas características básicas da cultura política nas cidades de Curitiba e Porto Alegre, analisando as suas diferenças e convergências como formas locais complementares de manifestação da conquista da cidadania, em distintos contextos histórico-sociais, durante o processo de democratização da esfera pública. Este trabalho se opõe aos estudos empíricos convencionais da cultura política, inspirados nas teorias da modernização, argumentando contra o viés determinista desses estudos, e os procedimentos de hipergeneralização por eles geralmente adotados. $\mathrm{O}$ estudo argumenta por uma abordagem que retrate e interprete o pluralismo constitutivo da cultura política, expresso no exercício da cidadania durante os processos de democratização.
\end{abstract}

Palavras-chave: modernização, democratização, cultura política e sub-culturas, cidadania, contextos histórico-sociais, pluralismo.

\section{Introdução}

Este estudo sugere que a democratização cultural acompanha a mudança do regime político, sob formas e conteúdos específicos do exercício da cidadania, em cada contexto histórico das "novas democracias". As evidências desse processo, em duas capitais do Sul do Brasil, indicam que a transformação da cultura política, em apoio à democracia, não segue um padrão linear pré-determinado -

\footnotetext{
* Este artigo apresenta os temas relacionados à cidadania, de um trabalho mais amplo de pesquisa, ainda a ser publicado. (Projeto CNPq \#: 523902/95-96). A base empírica dessa pesquisa foi apresentada com maior detalhamento e análise estatística em outro artigo (Krischke, 2004). O autor agradece os comentários dos colegas Stephen Chilton, Nythamar Oliveira e Wilson Mendonça, e de dois pareceristas desta Revista a versões anteriores do trabalho (sem contudo responsabilizá-los pelas limitações da versão atual).

** Professor, doutor em Ciências Humanas pela Universidade Federal de Santa Catarina Artigo recebido em 10 set. 2004; aprovado em 2 mar. 2005.
} 
como o sugerido pelas diferentes versões da teoria da modernização. Portanto, a finalidade do questionamento das abordagens à modernização que faremos aqui será interpretar adequadamente esses resultados de pesquisa, sobre as principais tendências em curso na cultura e no comportamento político, nas cidades de Curitiba e Porto Alegre, e as diferenças (e/ou semelhanças) que existem entre elas. A primeira parte do trabalho apresenta as linhas gerais da interpretação convencional da mudança e modernização cultural, que foi testada na pesquisa. A segunda parte apresenta resultados encontrados na pesquisa que, em sua maioria, contradizem essa interpretação. A sugestão final é que certos atributos centrais da cultura democrática - como o pluralismo, a tolerância e a capacidade de participação podem surgir em contextos históricos diferentes, relacionados a experiências diversas de exercício da cidadania e acesso à esfera pública.

\section{Modernização e cidadania ${ }^{1}$}

Sabemos que as teorias da modernização dos anos 50 e 60 adotaram um determinismo socioeconômico e político-cultural que hoje consideramos datado pelas ilusões do pós-guerra (Cf. Andrade, 1979; Lindenberg, 1990). Pensava-se, então, que o desenvolvimento socioeconômico exibiria uma capacidade integrativa ilimitada, difundindo o crescimento, a riqueza, a tolerância e a liberdade política - e... até a felicidade pessoal entre a população da América Latina. É certo também que esse determinismo não era apenas econômico, pois baseava-se na suposição de que o desenvolvimento da economia e da tecnologia viria acompanhado de mudanças sociais, políticas e culturais que retirariam a sociedade de seu legado tradicional, para adotar os padrões culturais e institucionais vigentes nos países centrais e democráticos do ocidente (Parsons, 1951, p. 182-191; Lipset, 1960).

A seguir veremos que essa perspectiva é compartilhada explicitamente por Ronald Inglehart (1997), que vincula a emergência de uma nova cultura - denominada "pós-materialista" - entre a juventude do mundo inteiro, a essa maior afluência e sofisticação 
socioeconômica, política e cultural, inicialmente apenas encontrada nos países centrais do ocidente. Desde já devemos reconhecer que, a partir de diversas perspectivas teóricas e com abundante base empírica, vários estudiosos da democratização na América Latina (por exemplo: Remmer, 1990; Bermeo, 1992; Geddes, 1995; Munck, 1996; Przeworski \& Limongi, 1993) têm refutado explicitamente as teses de Lipset e outros, acerca dos "condicionantes socioeconômicos da democracia”. E mesmo Lipset e seus seguidores (por exemplo, Diamond, 1991) têm matizado sua abordagem, no sentido de "não pretender que apenas o desenvolvimento econômico produza a democratização (...)" (Lipset, Seong, Torres, 1993, p. 156).

Mas o fato é que a utilização que fazem estes últimos autores, dos indicadores socioeconômicos (e outros de caráter político, elaborados pela Freedom House) padece de um viés etnocêntrico e determinista, que tem merecido a crítica metodológica de vários estudos (por exemplo: Escobar, 1992, p. 433-34; Somers, 1995; Munck, 1996, p. 24-25; Krischke, 2001). Especificamente, essa forma de determinismo considera a modernização como decorrente de forças externas materiais que se impõem à população, em nome de um "progresso" econômico e tecnológico aparentemente inelutável. Isto resultaria em novas formas de socialização (por exemplo, através da mídia eletrônica e informatização) - sem a mediação explícita de processos históricos de aprendizado e elaboração cultural intersubjetiva, em que os indivíduos estivessem envolvidos como participantes ativos. Por exemplo, esses estudos tendem a considerar o apoio à democracia como resultado mais ou menos mecânico, de um "equilíbrio multicausal" entre o sistema sociocultural e o desenvolvimento político-econômico.

Quanto à interpretação da cidadania nos processos de modernização, Conover \& Searing (1995, p. 42) propõem um marco de referência conceptual para o seu estudo, que combina os níveis de análise agregada e individual. O primeiro nível considera os fatores políticos (características do regime, da liderança e da legislação) e os fatores socioeconômicos (características das comunidades e instituições sociais, suas tradições e valores culturais). Todos esses 
fatores resultariam em processos de socialização determinantes das características individuais (predisposições psicológicas, identidades grupais, valores e orientações, etc.) e dos perfis da cidadania (senso de cidadania e orientações cívicas, etc.). Tais características dos indivíduos, por sua vez, influenciariam (e também receberiam influência) do seu comportamento político enquanto cidadãos (participação política e comportamento cívico). Sendo que a observação desses comportamentos, por último, permitiria confirmar a análise dos fatores agregados, políticos e socioeconômicos, considerados no início da proposta.

Por certo, essa proposta é uma abordagem funcionalista ao estudo da cidadania, como as que Margareth Somers (1995, p. 229) criticou vigorosamente enquanto "rede conceptual estruturada (ou modelo de cultura política) da teoria anglo-americana sobre a cidadania". ${ }^{2}$ Neste trabalho queremos sugerir a necessidade de dispensar a abordagem funcionalista (e sua teleologia da modernização), de modo a avaliar corretamente as mudanças culturais e do comportamento político, expressas nas experiências de construção da cidadania em Porto Alegre e Curitiba. Para isso, sintetizaremos inicialmente a abordagem à modernização socioeconômica e político-cultural, proposta por Ronald Inglehart.

Inglehart dedicou um de seus livros mais abrangentes (Modernization and Postmodernization: cultural, economic and political change in 43 societies, 1997) a uma retomada explícita da teoria da modernização. Para isso, lança mão da massa de dados do World Values Survey (pesquisa mundial sobre valores) para afirmar sua interpretação da mudança cultural nos valores das populações, com base em duas hipóteses: a de incidência da "escassez", e a dos efeitos e períodos de "socialização", entre diferentes estratos de idade ou gerações. A hipótese de escassez postula que "as prioridades do indivíduo refletem o seu ambiente socioeconômico". A hipótese de socialização postula que "em grande medida, os valores básicos dos indivíduos refletem as condições prevalecentes durante o período anterior à sua vida adulta" (Echegaray, Toso \& Krischke, 1998). ${ }^{3}$ 
Estas duas hipóteses orientam o argumento de Inglehart de que, quando as necessidades físicas e econômicas são apenas parcialmente satisfeitas durante a fase pré-adulta, a pessoa colocará maior valor na segurança física e econômica, ao atingir a idade adulta. Por isso, essa pessoa será considerada "materialista", enquanto "pósmaterialistas" seriam aqueles que preferem objetivos e valores menos tangíveis, pois tiveram assegurada sua segurança física e econômica, durante a idade pré-adulta. Estes "pós-materialistas" estariam mais preocupados com a qualidade de vida, a afetividade e a estética do que com considerações de ordem econômica e material.

Inglehart testou inicialmente suas hipóteses na Europa e demais países centrais do ocidente, onde postulou que as gerações nascidas no pós-guerra gradualmente teriam passado (em parte, mas de modo crescente) a adotar valores "pós-materialistas". Também postulou ali que esta tendência estava relacionada a atitudes participativas, na esfera pública em âmbito local, e em movimentos sociais dos anos 70 e 80, movimentos pacifistas, ecológicos, de gênero, minorias raciais, culturais, etc. (Clark \& Inglehart, 1990). Foi testada também a influência de fatores de curto prazo, como a dos ciclos de recessão econômica, que minoravam a tendência ao pós-materialismo, sendo que esta depois retornava, passado o ciclo recessivo. A série longitudinal da pesquisa, realizada regularmente desde a metade dos anos 70, também postulou que a tendência ao pós-materialismo não era apenas um fenômeno juvenil que acaso desaparecesse na fase adulta, pois as gerações que adotaram esses valores tenderiam a persistir no seu apoio.

As alternativas utilizadas como questões de pesquisa são, em geral, as quatro empregadas originalmente por Inglehart (que, posteriormente, as ampliou para doze, com mais dois conjuntos de quatro alternativas, para testar a coerência dos entrevistados). No primeiro conjunto, os entrevistados são convidados a selecionar, entre quatro possibilidades, por ordem de prioridade, quais deveriam ser os dois principais objetivos no país: 1) manter a ordem; 2) maior participação da população nas decisões importantes do governo; 3) combater a inflação; 4) proteger a liberdade de expressão. Os 
entrevistados que selecionam "manter a ordem" e "combater a inflação" são classificados como materialistas; e aqueles que escolhem "maior participação" e "liberdade de expressão" são classificados como pós-materialistas. As quatro combinações restantes são classificadas como "mistas". Os outros dois conjuntos de alternativas, que acrescentou posteriormente, apenas repetem a mesma dicotomia, usando palavras diferentes. ${ }^{4}$

No livro de 1997, Inglehart trata de ampliar seu argumento, com dados da pesquisa mundial sobre valores, levantados cada cinco anos, em amostras nacionais da população em 43 países, inclusive quatro da América Latina (Argentina, Brasil, Chile e México). Nos países do chamado terceiro mundo, assim como na Europa oriental, a tendência em apoio aos valores "pós-materialistas" é considerada incipiente, fato geralmente atribuído pelo autor à incidência de fatores de insegurança econômica, política e material na fase pré-adulta dos entrevistados (a hipótese de socialização). Nesse livro, Inglehart expande o seu argumento, explicitando a teoria em termos de "modernização e pós-modernização". Assim fazendo, assume sua vinculação com as teorias anteriores da modernização, que busca adaptar à sua proposta, tentando matizar o viés determinista dessas teorias.

A posição formal de Inglehart, logo no início do livro, é aparentemente crítica ao viés determinista dos estudos convencionais da modernização, afirmando que "não assumimos o determinismo, econômico ou cultural: nossos resultados sugerem que as relações entre valores, política e economia são recíprocas, e a natureza exata desses vínculos em cada caso é uma questão empírica, antes que algo a ser decidido a priori" (p. 4). O autor encaminha a seguir sua proposta de "análise funcional e síndromes de mudança previsíveis" (p. 14-17), pois "todo sistema econômico e político tem um sistema cultural que o legitima (...) O processo não é teleológico, mas opera como se fosse: as sociedades com sistemas legítimos de autoridade têm mais chances de sobrevivência que aquelas que não os têm" (p. 15). Mas, buscando superar o funcionalismo standard das teorias anteriores sobre a modernização, a mudança da cultura atual para o 
pós-materialismo é vista como "mutações [que] não acontecem para servir a uma função, mas [que] sobrevivem e se difundem porque a servem" (p. 16).

Inglehart busca, portanto, escapar do estigma determinista através de uma estratégia evasiva, em que tenta abrigar-se na noção de "equilíbrio homeostático" da teoria dos sistemas (Johnson, 1966). Mas interessa salientar que toda essa preocupação multicausal com o equilíbrio funcional não o faz descartar os "condicionantes socioeconômicos" estipulados pela teoria da modernização, antes ao contrário. ${ }^{5} \mathrm{E}$ grande parte do livro dedica-se a contrastar a busca pela segurança material, típica da modernidade, com a crescente ênfase cultural na qualidade de vida, típica da chamada pósmodernidade.

A abordagem enfatiza a existência de duas formas ou modelos contrastantes de sociedade, cada uma com suas próprias condições de desenvolvimento socioeconômico e político-cultural, sendo o fiat da transformação de uma em outra os processos de industrialização e diversificação sociocultural, finalmente resultantes na sociedade pós-moderna e pós-materialista. Tudo isso no velho estilo dualista das teorias da modernização.

A seguir, se expõem os dados de pesquisa em que se buscou testar essas limitações.

\section{Os casos de Curitiba e Porto Alegre}

Desde há alguns anos têm sido testadas, de modo preliminar, as hipóteses de Inglehart para o caso brasileiro, encontrando contudo resultados muito parciais e bastante contraditórios (Echegaray, Krischke \& Toso, 1998; Krischke, 2000). Principalmente, surgiram dúvidas sobre a capacidade de generalização dos dados levantados com as alternativas de Inglehart, tendo em vista a provável diversidade de compreensão dos entrevistados acerca dessas categorias. Em razão dessas dificuldades de generalização planejamos uma pesquisa de campo comparando as características da cultura política nas 
cidades de Porto Alegre e Curitiba. A finalidade dessa escolha foi superar as tendências hipergeneralizantes dos métodos usuais na pesquisa empírica da cultura política (Krischke 2001), realizando o trabalho de campo em contextos histórico-culturais claramente contrastantes e delimitados.

Neste sentido, foi importante estabelecer, de modo preliminar, como as populações das duas cidades entendiam as questões formuladas por Inglehart. Para aferir essa compreensão por parte dos públicos de Curitiba e Porto Alegre, realizamos debates com grupos focais em separado, com duas faixas etárias de participantes em cada cidade - onde incluímos a discussão de outros temas, referentes ao entendimento da democracia, da política, e das condições gerais de vida em cada cidade - além das alternativas sobre "materialismo/pós-materialismo". ${ }^{6}$ A atividade dos grupos possibilitou também criar um artefato de pesquisa, em certo sentido homólogo ao que Habermas denomina "situação ideal de discurso" (ou "posição originária" segundo Rawls), em que os participantes são convidados a situar-se e a debater eqüitativamente as normas vigentes no seu cotidiano. ${ }^{7}$ As conclusões principais dos grupos foram assim sintetizadas por Fátima Quintal, coordenadora dessa etapa:

"Poder-se-ia dizer que, tanto em uma quanto em outra cidade, ao menos em parte, os moradores, incorporaram em suas vidas, ao longo dos anos, os valores de parte da ideologia dominante, fruto em grande medida das políticas públicas em vigor. Os governos municipais nas duas cidades, ao longo das duas últimas décadas, ocuparam e ocupam pólos opostos, seja no sistema ideológico, seja na maneira de implantação de seus projetos e, conseqüentemente, em termos do espaço considerado permitido e aceitável e que é destinado à participação das pessoas na vida pública e cotidiana". (Quintal, 2001, p. 24) ${ }^{8}$

Essa interpretação geral dos grupos, dos quais veremos logo alguns detalhes, veio confirmar inicialmente a hipótese traçada pela pesquisa, de que "subsiste no interior da sociedade brasileira uma relativa pluralidade de matrizes valorativas e atitudinais relevantes no âmbito político, que poderíamos chamar de subculturas políticas. Tal diversidade tem suas origens nas profundas mudanças da 
sociedade brasileira nos últimos 30 anos, que implicam diferentes modos de viver a política e de relacionar-se com o mundo público em geral. Distinções podem também ser observadas nos perfis da vida associativa e naquilo que poderia se denominar, de forma genérica, de formatos dos espaços públicos locais". ${ }^{9}$ Um dos pontos de mudança cultural previstos pela pesquisa seria em termos geracionais, considerando a diversidade dos contextos históricos de socialização, em cidades que passaram por trajetórias políticas diferentes.

As conclusões gerais dessa etapa de estudo com grupos focais (e das entrevistas individuais com os participantes) foram muito importantes para orientar metodologicamente a fase seguinte da pesquisa (estudo por survey da população). ${ }^{10}$ Em primeiro lugar, decidimos manter as quatro escolhas alternativas apresentadas originalmente por Inglehart, mas propondo aos entrevistados uma única opção apenas - em lugar das duas pedidas por Inglehart, em ordem de prioridade. A intenção desse procedimento foi evitar ilações que tenderiam a enviesar os resultados, através da categoria de respostas "mistas" (suposta incoerência entre uma prioridade "materialista" e outra "pós-materialista") - que tem sido interpretada por Inglehart em termos de uma "transição" entre as duas situações, o que tem sido criticado por vários autores (Brown \& Carmine, 1995; Davis \& Davenport, 1999; Tranter \& Western, 2002). ${ }^{11}$ Além disso, as interpretações que os grupos focais fizeram dessas alternativas foram muito diversificadas, e às vezes, inclusive, opostas entre si. Portanto, como segundo ponto de reformulação metodológica, tal diversidade de interpretação dessas alternativas pelos membros dos grupos focais, somou-se ao levantamento de outros valores surgidos nesses debates, como veremos a seguir.

Quanto ao primeiro ponto de revisão, os resultados do survey mostram que não existe diferença significativa entre as duas cidades, no que respeita à adesão a valores supostamente "materialistas" e "pós-materialistas". Quando confrontados com as alternativas de Inglehart, ambos os públicos seriam majoritariamente "pósmaterialistas" - se quiséssemos continuar usando essas categorias embora seja necessário interpretar esses dados diferentemente, como 
especificaremos ao final. Resultado semelhante se obteve ao correlacionar esses mesmos dados do survey por faixa etária, na população de cada cidade (ver a Tabela 4, ao final desta seção). $\mathrm{Ou}$ seja, não houve significação estatística nas diferenças entre as faixas de idade, com respeito à adesão a valores supostamente "materialistas ou pós-materialistas" - embora houvesse variações sugestivas, diferentes das expectativas de Inglehart, que iremos considerar.

Quanto ao segundo ponto de revisão metodológica, os valores relevantes que surgiram nos debates entre os participantes dos grupos focais de ambas as cidades foram apresentados como uma lista aos entrevistados pelo survey, da qual foram convidados a escolher as cinco alternativas que consideraram principais (sem ordem de prioridade) para "a construção de uma sociedade ideal". Nos resultados dessas escolhas se constata que quatro desses valores principais são majoritários e comuns às duas cidades. Os cinco valores principais (esses quatro escolhidos em comum, mais o quinto também enfatizado separadamente em cada cidade) são mostrados na Tabela 1.

\section{Tabela 1 - Importância dos valores para construção de uma sociedade ideal}

\begin{tabular}{|l|c|l|c|}
\hline \multicolumn{2}{|c|}{ Porto Alegre } & \multicolumn{2}{c|}{ Curitiba } \\
\hline Justiça & $78 \%$ & Justiça & $8 \%$ \\
\hline Igualdade & $58 \%$ & Igualdade & $9 \%$ \\
\hline Liberdade & $49 \%$ & Desenvolvimento econômico & $8 \%$ \\
\hline Desenvolvimento econômico & $44 \%$ & Liberdade & $2 \%$ \\
\hline Respeito ao meio ambiente & $41 \%$ & Disciplina & $4 \%$ \\
\hline
\end{tabular}

A convergência entre as escolhas da população das duas cidades, selecionando conjuntamente quatro dos cinco valores como prioritários, é decisiva, e será considerada a seguir. Mas as diferenças entre as escolhas das duas populações (quinto valor selecionado) 
também são muito significativas e devemos enfatizá-las aqui. Diferentemente dos que responderam em Porto Alegre, os entrevistados de Curitiba não escolheram o valor do respeito ao meio ambiente como um dos cinco mais importantes para a construção da "sociedade ideal", e sim a disciplina. Isto reafirma o observado na dinâmica dos Grupos Focais - onde a manutenção da ordem institucional, pela organização do convívio cotidiano, cumprimento de regras sociais, ordenamento, autoridade, hierarquia e deferência nas relações entre as pessoas, foram pontos muito presentes e valorizados entre os participantes. ${ }^{12}$ A valorização da justiça, igualdade, liberdade e desenvolvimento econômico aparece aqui ancorada na disciplina como mediadora das relações sociais.

Em Porto Alegre, a valorização do respeito ao meio ambiente, associada aos demais valores, - bem como a ênfase maior conferida aos valores da igualdade e liberdade - sugerem uma representação acerca da "sociedade ideal" que contempla a inserção de novos valores ético-sociais, e a ressignificação dos demais valores, onde a questão da qualidade de vida toma peso. A importância dada ao desenvolvimento econômico aparece assim qualificada pela preocupação com o meio ambiente. Isto, aliás, parece inserir-se em um "projeto coletivo" mais amplo, tal como o que alguns dos participantes dos grupos focais, entrevistados anteriormente em Porto Alegre, haviam tratado de enfatizar. Esse projeto, longe de significar uma homogeneização dos debates, significou também, na atividade dos grupos, uma forte tendência à interlocução argumentativa, buscando exercer e aprimorar o respeito à diferença. ${ }^{13}$

Considerando essa diferença inicial entre os valores mais escolhidos nas duas cidades, buscamos estudar a sua configuração de conjunto, com outros valores também selecionados na lista, em cada uma das cidades. Para isso utilizamos uma técnica estatística chamada Cluster Analysis, que permite visualizar a relação dos valores entre si, a partir da composição de fatores que se agrupam por ordem de proximidade, nas escolhas feitas pelos entrevistados. Aqui, a distância indica oposição, ou seja, uma tendência à eleição de um conjunto em detrimento de outros. Assim observamos em Porto 
Alegre a formação de um fator composto pelos valores da liberdade, igualdade e justiça, que podemos denominar de valores ético-sociais, e a formação de um fator menos coeso, porém importante, composto pelos valores do desenvolvimento econômico e do respeito ao meio ambiente - que poderíamos denominar, pela sua pertinência, como valores do desenvolvimento sustentável. Estes dois fatores são destacados na análise de Cluster, em contraste com os outros valores, indicando uma tendência à eleição do conjunto de valores ali inseridos.

Em Curitiba, pudemos observar a formação de fatores que dão visibilidade a diferenças sutis, porém importantes para pensar e demarcar diferenças valorativas, na identidade dos habitantes de cada cidade. Também aqui, visualiza-se a formação de dois importantes fatores que se opõem a todos os outros valores. Um primeiro fator é composto dos valores desenvolvimento econômico e justiça, que aliam a idéia de "progresso" à de justiça social; o segundo fator é composto pelos valores liberdade, igualdade e disciplina, que aliam valores éticosociais à "manutenção da ordem". A formação destes fatores confirma indicações de diferenças na representação da "sociedade ideal" entre os habitantes das duas cidades - tal como fora sugerido pelos debates nos grupos focais.

Partindo dessa constatação geral, da existência de matrizes culturais diferentes, dos valores prioritários em cada uma das duas cidades, é necessário contudo assinalar as similaridades entre as respostas dos entrevistados das duas cidades. Em parte ao menos, essas semelhanças relacionam-se à escolha conjunta que fazem dos mesmos valores prioritários - ou, ainda, a interpretações e conotações complementares dos mesmos valores, no contexto hstórico-cultural específico de sua cidade. Por outro lado, há também diferenças contrastantes entre outras respostas e temas enfatizados nas duas cidades: Além disso, há ainda questões relacionadas à vida política e sua prática, nas preferências dos entrevistados, que receberam atenção especial. Essas semelhanças e diferenças entre as opções dos entrevistados, suas experiências práticas nos grupos de idade em cada cidade, e também em conjunto nas duas cidades, serão tratadas a seguir. 
Por exemplo, foi perguntado aos entrevistados nas duas cidades a importância que atribuíam à política, e o reconhecimento dessa importância foi amplamente majoritário, sendo a importância da política relativamente mais valorizada em Porto Alegre $(73 \%)$ do que em Curitiba (66\%). Observa-se, também, um maior reconhecimento da importância da política entre os mais jovens, nas duas cidades, diminuindo à medida em que a faixa etária aumenta.

Tabela 2 - Valorização da política por faixa etária

\begin{tabular}{|c|c|c|c|c|}
\hline & até 28 anos & de 29 a 44 anos & de 45 em diante & \\
\hline \multirow[t]{3}{*}{ muito importante } & 233 & 210 & 195 & 638 \\
\hline & $36 \%$ & $33 \%$ & $31 \%$ & $100 \%$ \\
\hline & $74 \%$ & $67 \%$ & $66 \%$ & $69 \%$ \\
\hline \multirow[t]{3}{*}{ mais ou menos importante } & 63 & 58 & 54 & 175 \\
\hline & $36 \%$ & $33 \%$ & $31 \%$ & $100 \%$ \\
\hline & $20 \%$ & $18 \%$ & $18 \%$ & $19 \%$ \\
\hline \multirow[t]{6}{*}{ nada importante } & 20 & 45 & 46 & 111 \\
\hline & $18 \%$ & $40 \%$ & $41 \%$ & $100 \%$ \\
\hline & $6 \%$ & $14 \%$ & $16 \%$ & $12 \%$ \\
\hline & 316 & 313 & 295 & 924 \\
\hline & $34 \%$ & $34 \%$ & $32 \%$ & $100 \%$ \\
\hline & $100 \%$ & $100 \%$ & $100 \%$ & $100 \%$ \\
\hline
\end{tabular}

Para verificar o grau de tolerância política dos entrevistados, foi formulada uma questão onde se pedia que o entrevistado indicasse a frase que considerava mais próxima às suas concepções. A tolerância é um importante indicador de democratização cultural, caracterizando uma disposição para conviver com o direito à diferença. A adesão a este índice foi alta em ambas as cidades, não havendo diferença significativa entre as respostas das duas populações. Contudo, correlacionando esses dados, com a faixa etária, em conjunto nas duas cidades, observa-se uma maior tolerância política (estatisticamente significativa) nos entrevistados com até 28 anos de idade (70\%), do que nas demais faixas etárias (57\%).

Já é conhecida, de pesquisas anteriores, a tendência a uma falta de interesse em geral da população pela política em seu formato 
institucional. Porém, quando a atividade política se constitui considerando dimensões culturais e simbólicas (como no caso da defesa do meio ambiente, ou dos valores prioritários), os entrevistados tendem a declarar participação mais efetiva na política. Até o final desta seção estaremos apresentando algumas correlações entre essas respostas dos entrevistados, para debater o seu significado na cultura política das duas cidades..$^{14}$

Com referência à lista inicial de valores, correlacionada à faixa de idade, os apoios à liberdade e igualdade analisados por cidade alcançam maior significado em Porto Alegre. Embora as diferenças entre as duas faixas de idade mais jovens sejam pequenas, nas duas cidades ambas se diferenciam da faixa dos mais idosos - cuja omissão na escolha desses valores alcança significado estatístico. Estes entrevistados com mais de 45 anos, nas duas cidades, enfatizam mais o valor da justiça, e, surpreendentemente, os da preservação da natureza e meio ambiente. $\mathrm{O}$ valor do desenvolvimento econômico é principalmente enfatizado, nas duas cidades, pelos entrevistados de idade intermediária (dos 29 aos 44 anos). Esta análise estatística mais fina, por idade dos entrevistados em cada cidade, indica que devemos matizar as configurações iniciais, que fizemos acima, através da Análise de Cluster - estabelecendo matrizes das diferenças gerais de opção entre as duas cidades, na lista inicial de valores.

Mencionamos acima que as escolhas referentes ao denominado "materialismo/pós-materialismo" não permitem encontrar diferenças com significação estatística, seja entre as populações das duas cidades, seja entre faixas etárias diversas em cada cidade - o que contradiz (ou ao menos questiona radicalmente, como fizeram também outros autores, como Kaase, 1999) ${ }^{15}$ as hipóteses de Inglehart. No entanto, como veremos a seguir, a partir da clivagem geracional encontramos elementos que permitem indagar acerca da eventual formação de uma subcultura etária em âmbito regional, incluindo tanto Curitiba como Porto Alegre.

Quando indagados sobre suas alternativas desejáveis de inserção social no tempo livre, os entrevistados de ambas as cidades 
enfatizaram principalmente o lazer e as relações afetivas (Tabela 3). Este é um indicador importante, tanto de insatisfação com o presente, como de motivação para inovar no futuro.

\section{Tabela 3 - Inserção em grupo ou atividade no tempo livre}

\begin{tabular}{|c|c|c|c|}
\hline \multicolumn{2}{|c|}{ Porto Alegre } & \multicolumn{2}{c|}{ Curitiba } \\
\hline Lazer e relações afetivas & $\mathbf{6 9 \%}$ & Lazer e relações afetivas & $\mathbf{6 6 \%}$ \\
\hline $\begin{array}{c}\text { Atividades assistenciais e } \\
\text { religiosas }\end{array}$ & $49 \%$ & $\begin{array}{l}\text { Atividades assistenciais e } \\
\text { religiosas }\end{array}$ & $55 \%$ \\
\hline Procuraria outro emprego & $29 \%$ & Procuraria outro emprego & $26 \%$ \\
\hline Defesa do meio ambiente & $28 \%$ & Defesa do meio ambiente & $21 \%$ \\
\hline Atividades políticas & $9 \%$ & Atividades políticas & $10,0 \%$ \\
\hline Outras & $4 \%$ & Outras & $4 \%$ \\
\hline
\end{tabular}

Esta prioridade do lazer e relações afetivas encontrou uma correspondência com a faixa etária dos entrevistados nas duas cidades, sendo que os dois grupos de idade com menos de 45 anos alcançaram o mesmo índice positivo de significação - entre os mais idosos essa preferência não foi significativa. Essa prioridade no uso do tempo livre correlaciona-se positivamente com as escolhas sobre valores da lista inicial, tais como alegria, prazer, auto-realização e meio ambiente. Estes valores estão entre os mais preferidos pelos mais jovens (até 28 anos) em ambas as cidades, embora nem sempre sejam essas as escolhas de valores majoritárias, mesmo nessa faixa de idade. Destaca-se também a preferência dos mais jovens pela defesa do meio ambiente no uso do tempo livre, em correspondência com a escolha desse mesmo valor na lista inicial.

Para o conjunto dos entrevistados, de todas as idades e nas duas cidades, a opção de tempo livre em atividades políticas correlaciona-se positivamente com a ênfase que já vimos acima, acerca da importância da política. Por sua vez, a opção no tempo 
livre por atividades assistenciais e religiosas é priorizada principalmente em Curitiba por aqueles que escolheram entre seus valores da lista inicial o temor a Deus ou a religiosidade. Significativamente, aqueles que optam por atividades políticas em Curitiba, e os que escolhem lazer e relações afetivas em Porto Alegre, não selecionam o temor a Deus na lista inicial de valores. A seleção pelos mais jovens de atividades políticas como opção de tempo livre, também correlaciona-se positivamente com a escolha da liberdade na lista inicial de valores, opção que está também relacionada nas duas cidades com a importância da democracia como prioridade.

Esse conjunto de dados permite perceber tendências emergentes na juventude, que unem a insatisfação com o presente à busca por soluções inovadoras. É certo que estas tendências não assumem sempre o perfil nítido de um "projeto coletivo" - como denominaram alguns entrevistados nos grupos focais de Porto Alegre o apoio às administrações do PT (Márcia R. Dias, 2003, realizou pesquisa sobre este tema). Mas é possível sugerir que essas tendências inovadoras, em ambas as cidades, oferecem suporte motivacional para uma subcultura em formação, que pode inclusive estar já alcançando uma expressão política e eleitoral. É assim que o interesse pela política, que supera entre os mais jovens a tradicional rejeição das instituições por parte da população brasileira, pode unir-se aos valores do respeito ao meio ambiente, tolerância e auto-realização abrigando valores menos salientes (como o da alegria e outros, mais típicos dos jovens) junto aos valores majoritários entre o conjunto dos entrevistados das duas cidades, a favor da justiça, liberdade, desenvolvimento e igualdade.

Estes últimos valores, que recebem o apoio principal da maior parte da população, passam a receber uma nova conotação emergente, a partir das novas gerações. E tal inovação retoma também as categorias de Inglehart, sobre "materialismo/pós-materialismo", dandolhes outro contexto e significado. A Tabela 4 relaciona as respostas a essas alternativas por faixa etária, conjuntamente nas duas cidades, mostrando marcantes contrastes com os supostos de Inglehart. 


\section{Tabela 4 - Objetivos mais importantes para o Brasil por faixa etária - Curitiba e Porto Alegre}

\begin{tabular}{|c|c|c|c|c|}
\hline Objetivos mais importantes para o Brasil & até 28 anos & de 29 a 44 anos & de 45 em diante & Total \\
\hline \multirow{2}{*}{$\begin{array}{l}\text { Economia estável, crescimento econômico e } \\
\text { combate à inflação }\end{array}$} & 98 & 109 & 89 & 296 \\
\hline & $31 \%$ & $35 \%$ & $30 \%$ & $32 \%$ \\
\hline \multirow{2}{*}{$\begin{array}{l}\text { Manter a ordem fazendo valer a autoridade do } \\
\text { governo }\end{array}$} & 8 & 9 & 29 & 46 \\
\hline & $2 \%$ & $3 \%$ & $10 \%$ & $5 \%$ \\
\hline \multirow{2}{*}{$\begin{array}{l}\text { Sociedade onde pessoas sejam mais } \\
\text { importantes que dinheiro }\end{array}$} & 115 & 84 & 98 & 297 \\
\hline & $36 \%$ & $27 \%$ & $33 \%$ & $32 \%$ \\
\hline \multirow{4}{*}{$\begin{array}{l}\text { Maior participação da população nas decisões } \\
\text { do país }\end{array}$} & 95 & 111 & 79 & 285 \\
\hline & $30 \%$ & $35 \%$ & $27 \%$ & $30 \%$ \\
\hline & 316 & 313 & 295 & 924 \\
\hline & $100 \%$ & $100 \%$ & $100 \%$ & $100 \%$ \\
\hline
\end{tabular}

Assim, relacionando as diferentes faixas etárias e os posicionamentos que os entrevistados assumem sobre os objetivos que consideram mais importantes para o País, podemos observar uma diferenciação entre os entrevistados mais jovens e os maiores de 45 anos. Estes últimos priorizam menos a participação política, e dão maior apoio à manutenção da ordem social e da autoridade, nas duas cidades. Por sua vez, os mais jovens (até 28 anos) e os de idade intermediária (de 29 a 44 anos) mostram pequena variação entre suas preferências - com a visível exceção do apoio à terceira alternativa ("pessoas mais importantes que dinheiro") onde inclusive as preferências dos maiores de 45 anos estão mais próximas às dos menores de 28. Contudo, como já foi mencionado acima, as diferenças que encontramos nesta Tabela 4 são pequenas e carecem de validação estatística.

Há porém outros resultados significativos, quando correlacionamos as opções dos entrevistados sobre os objetivos para 
o País com outras escolhas e respostas que expressaram as várias questões diferentes da pesquisa. Já vimos acima que o valor do desenvolvimento econômico esteve entre os cinco valores principais escolhidos por ambas as amostras, em Curitiba e Porto Alegre. Nos dados sobre a eleição dos objetivos principais para o País, por faixa etária, muitos dos que optaram pela estabilidade econômica e combate à inflação também escolheram o desenvolvimento econômico como uma das cinco prioridades na lista inicial de valores. Essa correlação positiva entre ambas as escolhas ocorreu em todas as faixas etárias nas duas cidades, mas resultou especialmente significativa no grupo de idade intermediária, entre os 29 e os 44 anos.

Em Curitiba, houve também uma correlação significativa para todos os grupos de idade entre a escolha do valor desenvolvimento econômico na lista inicial e a ênfase na maior participação da população como objetivo principal do País. A escolha do valor desenvolvimento econômico entre os cinco principais da lista inicial também alcançou uma correlação positiva com as respostas dos entrevistados em Porto Alegre a outras questões que enfatizaram a importância da política e a tolerância. Para usar os termos de Inglehart, temos aqui a ênfase em um valor "materialista" fortemente relacionada a objetivos que ele denominaria "pós-materialistas". Digase de passagem que outros pesquisadores, como Haller (2002), Marshall (1997) e Clarke (2000), também encontraram em seus estudos resultados que contradizem os supostos centrais de Inglehart.

No caso de Porto Alegre, os dados confirmam a prioridade do desenvolvimento, com um significado específico entre os setores mais politizados desta cidade - o que especifica melhor o que foi constatado acima pela Análise de Cluster. Contudo, os jovens de ambas as cidades (até os 28 anos) que escolheram o valor do trabalho entre os valores prioritários da lista inicial, também declaram preferência pela estabilidade econômica como objetivo principal para o País.

A difusão dessa escolha do valor do desenvolvimento econômico, entre todas as faixas de idade das duas cidade, embora com conotações variadas segundo a faixa etária, indica bem mais do 
que a sua importância central para todos os entrevistados. As diferenças de correlação dessa resposta com as eleições dos objetivos para o País em Porto Alegre e Curitiba (e outras variações, por grupos de idade, obtidas frente a outros temas da pesquisa) confirmam a existência, nas duas cidades, de matrizes ou conceptualizações diferenciadas do que seja o desenvolvimento - como já foi sugerido acima, pelas Análises de Cluster. De fato, essas variantes interpretativas, nas conotações com que se relacionam os valores considerados principais às atividades e orientações políticas, presumem a existência de experiências políticas contrastantes, que influenciam diversamente as opções da população, em cada cidade e segundo a faixa etária.

Algo semelhante se observa com outro exemplo diferente quanto à adoção dos valores principais - que é o caso do meio ambiente. A consideração deste caso é útil, por tratar-se de valor selecionado como prioritário apenas em Porto Alegre por todas as faixas de idade (ou seja, como um dos cinco valores principais mais escolhidos pela amostra da população, na lista inicial de valores). Contudo, na análise por faixa etária, em conjunto nas duas cidades, notamos o resultado, que mais acima consideramos surpreendente, do grupo de mais idosos (acima de 45 anos) declarar preferência significativa tanto pelo valor preservação da natureza como pelo valor meio ambiente - o que não acontece nas demais faixas de idade, pelo menos com índice semelhante de significação.

No entanto, no uso desejável do tempo livre, que expressa uma adesão potencial a atividades associativas, a faixa dos mais jovens das duas cidades, correlacionam positivamente essas opções com a escolha do valor meio ambiente. E quanto à alternativa de opção do tempo livre especificamente na defesa do meio ambiente, todos os que fizeram esta opção, de todas as idades, a correlacionam positivamente com a escolha do valor preservação da natureza como um dos principais na lista inicial de valores.

É claro que esses dados não são necessariamente contraditórios - por exemplo, há quem interprete a defesa do meio 
ambiente e a preservação da natureza como sinônimos, embora esta seja apenas uma entre outras interpretações. Mas essas diferenças de significação, nas correlações entre respostas sobre esses temas, nas duas cidades - em separado ou em conjunto - por um lado, e entre os diferentes grupos de idade, por outro lado, sugerem também (como já vimos acima no caso do valor desenvolvimento econômico) a existência de algo mais do que matrizes culturais diferentes em cada cidade. Essas matrizes ou configurações diferenciadas dos valores, entre as duas cidades, foram constatadas pela Análise de Cluster. Mas o que se evidencia agora é a existência de uma diversidade de conotação e contextualização política, investida nos valores meio ambiente e preservação da natureza.

Existe um debate amplo, na literatura especializada (que não podemos abordar neste espaço) sobre essa diversificação interpretativa-opondo, por exemplo, as políticas de conservacionismo às do preservacionismo; ou ainda as tendências ao "eco-capitalismo" às do "eco-socialismo", etc. (Cf. Alexandre, 2003). Essa diversidade doutrinária e prática merece ser melhor analisada, especialmente considerando as trajetórias diferentes de incorporação desses temas na agenda das administrações municipais, na expansão do seu debate público, e nas atividades associativas correspondentes à orientação dos movimentos ecológicos em cada cidade.

Seja qual for o resultado dos debates sobre o significado desses valores, é provável que tais diferenças tenham um impacto na orientação das políticas públicas e na atuação dos movimentos sociais. É, portanto, muito importante salientar a sua correlação positiva com a ênfase no emprego eventual do tempo livre nas diversas faixas etárias das duas cidades. Pois essas escolhas (e outras opções e alternativas políticas que estamos considerando) revelam a disposição dos entrevistados por práticas inovadoras, e um potencial engajamento coletivo - que serão certamente diferenciados em cada cidade e faixa etária, na solução dos problemas ecológicos (e outros tantos) que os afetam a todos. 
Portanto, começamos a perceber que as diferenças entre a cultura política em Porto Alegre e Curitiba pouco têm a ver com as hipóteses de Inglehart, estritamente consideradas, contendo até inversões de suas expectativas. Essas inversões de expectativa das hipóteses de Inglehart, a partir dos resultados desta pesquisa, começam a desvelar as aporias de hiper-simplificação e hipergeneralização da abordagem desse autor, porque prisioneira não apenas de um artefato metodológico residual (as respostas "mistas" ou contraditórias, interpretadas como "de transição", além de outros pontos relacionados pela crítica (ver Rahn \& Transue, 1998; Degraaf \& Evans, 1996; Cliquet, 1991; Stolle \& Hooghe, 2002; Echegaray \& Armento,2000), mas sobretudo porque é caudatária de uma teleologia determinista do "progresso" socioeconômico e material, que não encontra respaldo nos fatos.

Realmente, não há diferença significativa entre os indicadores socioeconômicos e demográficos de Porto Alegre e Curitiba (índices de renda, ocupação, industrialização, escolaridade, etc.) - dados geralmente considerados cruciais para sustentar as mudanças de modernização da cultura política, dentro da abordagem convencional (Krischke, 1997). Portanto, as escolhas principalmente dos menores de 45 anos, priorizando alternativas que Inglehart consideraria "pósmaterialistas", podem relacionar-se a outros fatores do contexto político e histórico-cultural, que afetam significativamente as posições de jovens e adultos, tanto em Curitiba como em Porto Alegre. Estes fatores relacionam-se ao processo de democratização do País, que atua sobre as tradições culturais diferentes das duas cidades, bem como na diversidade das gestões administrativas e das experiências da cidadania em cada município.

Sintetizando o que vimos nesta seção, observamos que curitibanos e porto-alegrenses convergem suas preferências de valores ao redor da justiça, liberdade, desenvolvimento e igualdade, embora os primeiros apontem a disciplina e os segundos o respeito ao meio ambiente, respectivamente, como seu quinto valor prioritário. Estas escolhas já estavam, em parte ao menos, antevistas nas entrevistas e debates com os participantes dos grupos focais e foram, então, 
analisadas como decorrência dos contextos histórico-culturais de sua origem. No caso de Curitiba, há uma ênfase no cidadão como portador de direitos e obrigações, em contraste com a ênfase no "outro social", tendencialmente reconhecido em Porto Alegre como participante de um projeto coletivo. Essas ênfases contrastantes podem ser vistas como duas faces complementares do exercício da cidadania, que enfatizam seja o acatamento individual da lei, seja a sua fundamentação e aperfeiçoamento argumentativo na participação coletiva.

A realização do survey com amostras das duas populações também permitiu perceber as nuanças, às vezes sutis, com que essas matrizes distintas se manifestam nas faixas de idade. Mesmo quando certos valores são escolhidos preferencialmente pelos mais jovens, valores prioritários do conjunto das duas cidades correlacionam-se positivamente com as atividades eventuais de tempo livre e com outras importantes opções e experiências práticas da vida política principalmente entre as faixas etárias até os 44 anos de idade (embora haja exceções que são, também, importantes e devem ser melhor analisadas). Considerando o caráter prospectivo de mudança que essas escolhas sugerem (principalmente entre os menores de 45 anos), podemos indagar sobre seus efeitos e relações com um "pósmaterialismo" emergente.

Certamente, não se trata de esperar um efeito mecânico de causas materiais pré-existentes, mas de vislumbrar uma redefinição sustentável do desenvolvimento socioeconômico e político-cultural através do apoio dos cidadãos à convergência entre as suas visões da justiça, igualdade e liberdade - matizadas e diferenciadas a partir de cada contexto municipal - mas construindo e aprofundando, em conjunto, a democratização cultural e institucional desta região do País. O futuro dirá se essas tendências regionais emergentes encontrarão a progressiva institucionalização, que pode acompanhar sua maior expressão, representatividade e respaldo eleitoral na expansão e fortalecimento da esfera pública. 


\section{Conclusões}

Esta pesquisa revela que é manifestamente inadequada a abordagem da mudança cultural nos termos da autodenominada modernização - como se essa mudança decorresse apenas do progresso tecnológico e socioeconômico, ou de um "equilíbrio multicausal" adaptativo, entre a cultura e as estruturas/instituições sem considerar as experiências práticas da cidadania, nos seus efeitos e nas suas causas. Essa forma de pensamento, linear e determinista, que postula um único caminho e desenlace para os processos de democratização, não faz mais que renunciar a qualquer tentativa de explicação histórica para as diferenças e convergências entre culturas nacionais e subculturas regionais. Na verdade, durante os processos históricos de democratização da esfera pública e desenvolvimento da cidadania, tais peculiaridades não apenas persistem mas se especificam ainda mais naquilo de relevante que têm a contribuir.

Vimos acima que a ênfase comum de curitibanos e portoalegrenses nos valores prioritários da justiça, igualdade, liberdade e desenvolvimento econômico encontra nuanças significativas quando combinada (como eles mesmos fazem), com os valores também prioritários da disciplina (em Curitiba) e do meio ambiente (em Porto Alegre). E algo similar acontece quando esses valores são correlacionados com diferentes atitudes e opções, que caracterizam o perfil histórico do exercício da cidadania em cada cidade. O que esses fatos permitem constatar é que a conquista da cidadania alcança, nessas duas cidades, tanto sua manifestação individual (com evidência especial em Curitiba), como sua expressão enquanto agente (ou projeto) coletivo (enfatizada tendencialmente em Porto Alegre).

Essas conceituações diferentes da cidadania são, às vezes, consideradas faces complementares do seu exercício, pelo pensamento político ocidental. No dizer de Conover \& Searing (1995, p. 35), elas provém de "duas visões da cidadania que são bastante diversas, embora complementares: a 'comunitária' e a 'contratual' (...). A primeira visão origina-se no 'civismo republicano' (...que) exige uma cidadania ativa, fundada nos vínculos fraternais e de 
vizinhança, de tradições e atividades em comum (...). Por sua vez, a segunda perspectiva considera os cidadãos como indivíduos reunidos por um 'contrato social', sendo no cerne um pacto legal que levanta poucas demandas na esfera pública". Essas perspectivas se complementarão, na medida em que "tanto a cidadania comunitária como a contratual encorajem o desenvolvimento de orientações e valores cívicos" (por exemplo, tolerância, reciprocidade, etc.) (p. 45).

Mas não é o caso de sugerir que as diferenças no exercício da cidadania em Porto Alegre e Curitiba derivam funcionalmente dessas matrizes clássicas ou de sua combinação. Talvez a caracterização que John Rawls propõe aos atributos morais constitutivos da cidadania mostre melhor a sua necessária complementação, porque são atributos de cada indivíduo, no exercício dessa cidadania:

Como as pessoas podem participar plenamente de um sistema eqüitativo de cooperação social, atribuímos a elas duas faculdades morais (...) a capacidade de ter senso de justiça e a capacidade de ter uma concepção do bom senso de justiça é a capacidade de entender a concepção pública de justiça que caracteriza os termos eqüitativos de cooperação social, de aplicá-la e de agir de acordo com ela. (...) A capacidade de ter uma concepção do bem é a capacidade de formar, revisar e procurar concretizar racionalmente uma concepção de vantagem racional pessoal, ou bem. (Rawls, 1993, p. 62 da tradução brasileira)

Esta proposta de Rawls é uma ampliação da perspectiva contratual da cidadania, incluindo na esfera legal e institucional a necessária dimensão moral da justiça, capaz de reconhecer e acatar os diferentes interesses comunitários e as várias concepções do bem comum que os fundamentam. Neste sentido, a cidadania é construída e interpretada na pluralidade das suas manifestações de civismo, as quais são consentâneas com os resultados desta pesquisa.

Pois o que se observa nos dados da pesquisa é o fortalecimento, com ênfases diversas, de um fenômeno inovador, centrado no pluralismo doutrinário e político, o qual passa a convergir e a fundamentar a prática da democracia em âmbito municipal e regional. Constatamos na pesquisa um índice crescentemente majoritário de 
confiança na política, e de tolerância com a diferença, na população das duas cidades que estudamos. E essa tendência é promissora, porque relacionada a uma nova orientação cultural, emergente entre os setores mais jovens da sociedade - enfatizando a igualdade, a reciprocidade, e demais atributos da democracia - o que possibilita a sua crescente difusão em âmbito regional. ${ }^{16}$

A democratização da cultura política passa a ser vista, assim, como um processo necessário de revisão e atualização das tradições culturais da política, na própria vida e comportamento democrático dos cidadãos. Estas mudanças são reforçadas, portanto, pelas importantes características, mais (ou menos) democratizantes, das gestões político-partidárias encarregadas de sua implementação. Tais mudanças resultam - também, e talvez principalmente - das formas e conteúdos peculiares legados pela tradição política, na expansão e no fortalecimento do exercício local da cidadania (Habermas, 1979). ${ }^{17}$ Isso foi o que encontramos em curso de realização nesta pesquisa, quanto à democratização cultural e à construção da cidadania em Curitiba e Porto Alegre.

\section{Notas}

1 Devo agradecer aos colegas Aluir Toso, Fabian Echegaray e Sergio Costa, que colaboraram nas fases preliminares de elaboração do projeto de pesquisa aqui relatado. Principalmente agradeço à colega Louise Lhullier, que colaborou decisivamente na sua reformulação teóricometodológica, e orientou a realização do trabalho de campo. A colega Fátima Quintal coordenou a realização dos grupos focais. O doutorando Marcos Mesquita participou ativamente na sistematização e análise inicial dos dados do survey. Ana Lidia Brizola apoiou a coordenação administrativa e do trabalho de campo. Luis Claudio Messa atuou como bolsista de ajuda técnica na organização estatística dos dados do survey. As bolsistas de iniciação científica Giselle Cardoso, Carine Fernandes e Doris Waldow participaram em várias etapas da realização técnica e administrativa do projeto. O Instituto Ethos de Curitiba e o Instituto Meta de Porto Alegre proporcionaram apoio logístico, respectivamente, à realização do trabalho de campo e ao processamento estatístico dos dados. 
2 Para Somers (1995, p. 229), "esta rede conceptual consiste em uma estrutura narrativa acerca da cidadania anglo-americana, construída por uma epistemologia socionaturalista, cujos elementos são combinados para formar uma meta-narrativa, que vem limitando os estudos empíricos na área da Sociologia Política".

3 A hipótese de escassez implicaria em mudanças valorativas de curto prazo: períodos de escassez econômica (inflação, recessão, desemprego) aumentariam a tendência de apoio a valores materialistas (busca de segurança pessoal, material e política). Por outro lado, os períodos de prosperidade aumentariam a tendência de apoio aos valores pósmaterialistas (qualidade de vida, afetividade e estética). Contudo, a hipótese de socialização enfatiza os efeitos geracionais de longo prazo (apesar dos efeitos conjunturais de curto prazo, que modificam, reforçando ou mitigando, os efeitos ou atitudes básicas geracionais).

4 É necessário assinalar o procedimento hipergeneralizante de Inglehart, na sua aferição de valores a partir apenas de escolhas dos entrevistados entre essas poucas alternativas. Vários autores têm criticado esse procedimento, como Tranter \& Western (2002), Marshall (1997), etc. Aqui vale lembrar também a advertência de Habermas sobre o estudo dos valores, com conseqüências metodológicas que especificaremos adiante: "Os valores culturais (...) são, na melhor das hipóteses, candidatos a materializar-se em normas destinadas a expressar um interesse geral. Por conseguinte, é apenas relativamente a normas e sistemas normativos destacados da totalidade da vida social que os participantes podem tomar a distância necessária para adotar face a eles uma atitude hipotética (... a qual) estende-se apenas às questões práticas que se podem debater racionalmente, ou seja com a perspectiva de alcançar um consenso. Isto não se relaciona com a preferência de valores, mas com a validade das normas de ação“. (Habermas, 1989, p. 126-127, grifo no original)

5 O Capítulo 6 de seu livro dedica-se a esse ponto, e após apoiar-se nos dados e conclusões de Lipset e outros sobre os condicionantes socioeconômicos da democracia, afirma: "O desenvolvimento conduz à democracia desde que ocasione certas mudanças na cultura e na estrutura social, (...quando) mobiliza públicos massivos e tende a suscitar orientações culturais em apoio (à democracia)" (p. 161, grifo no original). O capítulo seleciona evidências desses resultados, principalmente no que se refere aos efeitos da industrialização sobre a cultura política e a estrutura social, mas não pode escapar ao leitor o caráter circular da argumentação. 
6 Foram realizados dois grupos com nove a dez participantes em cada cidade, um deles com pessoas de idade até 28 anos, e o outro com 29 anos ou mais. Houve uma distribuição eqüitativa por sexo, e cada grupo foi constituído em idênticas proporções por funcionários, estudantes e professores das Universidades Federal e Católica, em ambas as cidades. O debate era moderado por um membro da equipe de pesquisa, e circulava por temas relacionados a: democracia versus autoritarismo, valores e crenças políticas, e participação política e social (além da discussão das alternativas de Inglehart sobre "materialismo/pós-materialismo"). Foram também realizadas entrevistas individuais com cada membro dos grupos, com o objetivo de captar melhor as posições manifestadas durante os debates. Outro objetivo foi reconstruir as histórias de vida dos entrevistados, buscando captar os modos em que os contextos históricosociais influenciam a constituição de sua personalidade.

7 Este procedimento foi inspirado em uma proposta de interpretação da cultura política como "uma forma de relação 'compartilhada' apenas quando publicamente comum numa dada coletividade" (Chilton, 1990, p. 80). Esta "forma de relação" compartilharia "critérios de validade intersubjetiva" sobre normas de ação que sejam "públicas" e "comuns" entre os participantes dos debates. Pois as mesmas são: "(a) compreendidas como um entendimento comum; e, (b) usadas de fato pelos participantes para orientarem-se mutuamente em assuntos sóciopolíticos (como seu foco público de orientação)" (Ibid., grifos no original).

8 Esta interpretação refere-se aos debates sobre "Maior Participação da População", mas pode também ser extrapolada à de outros temas (Quintal, 2001, p. 24). "Nos moradores de Curitiba, os conteúdos dirigem-se a ações individuais, localizadas e isoladas, ações essas permeadas pela exigência da qualidade, do correto e do cumprimento das leis e direitos. Poder-se-ia dizer que focalizam no plano da garantia da materialização das leis e, quando necessária, uma atuação das pessoas, esta deveria se fazer na direção do cumprimento do previsto legalmente. Por outro lado, os participantes de Porto Alegre, acabam por refletir uma história continuada de um mesmo tipo de administração pública em que os canais de envolvimento e participação da população têm sido incentivados e se constituem em fortes baluartes da orientação política existente... Poder-se-ia dizer que a rede de relações sociais existente, incentivada e construída em Curitiba ao longo destes anos, criou uma identidade de cidadão participante como aquele afeito à defesa de seus direitos. Em certa medida, isto está coerente à acepção radical do termo cidadão, visto que ele se torna possível, somente, dentro do marco da 
individualidade. $\mathrm{O}$ social é compreendido na perspectiva de ações individuais corretas, legalmente amparadas e legitimadas pelo atendimento destas prescrições. Por sua vez, na cidade de Porto Alegre, a interlocução, o debate e a participação em esferas para além do individual têm sido incentivadas, de modo que o político e o social tenham sido construídos com um conteúdo da necessária existência do 'outro social, seja para delimitar e explicitar a diferença, seja para identificar os pares das ações, seja para serem encontradas ou fortalecidas estratégias de ação. Entretanto, isto, por si só, não significa que a igualdade de participação decorra naturalmente deste quadro. Na realidade, o plano da ação poderia estar mais próximo da dimensão da explicitação privada, no caso de Curitiba, e mais próximo da dimensão da exposição pública, na outra cidade."

9 Ver Costa (1996).

10 Os dados foram coletados em agosto de 2001, em Curitiba e Porto Alegre. O principal objetivo foi levantar dados que permitissem a análise de possíveis clivagens geracionais na cultura política nessas duas cidades. Paralelamente, buscava-se investigar a possibilidade de diferenças entre ambas, possivelmente relacionadas às repercussões histórico-culturais do processo de democratização na socialização política de seus habitantes. A população-alvo, nas duas cidades, foi constituída por pessoas de ambos os sexos, como escolaridade mínima de $2^{\circ}$ grau completo e que tivessem vivido na cidade onde foram entrevistados Curitiba e Porto Alegre - dos 10 aos 17 anos, no mínimo. Este último requisito está vinculado à importância atribuída às experiências vividas nessa faixa etária. Em Curitiba, a amostra foi constituída por 462 entrevistados, e em Porto Alegre, por 463 entrevistados, em pontos de alta circulação.

11 Tranter e Western (2002, p. 4) concluem: "By scoring the four item index for OLS regression analysis as a three category dependent variable (Inglehart) truncates variance on the dependent variable".

12 Participantes dos grupos focais em Curitiba: expressaram as falas seguintes, durante os debates e nas entrevistas logo a seguir: "[a disciplina] é seguir a lei"; "começa na comunidade e acaba no indivíduo"; "cultura conservadora"; "igreja, religião"; "ditadura = ordem"," transição gera instabilidade"; "geração do medo"; "preconceito e politicagem"; "corrupção, desconfiança"; "assaltos, insegurança"; "instituições dependem das pessoas"; "todas instituições perderam credibilidade"; "desenvolver a pessoa para desenvolver o mundo; do privado para o público." 
13 Eis algumas manifestações dos participantes nos grupos e entrevistas em Porto Alegre: "socialismo mais próximo da cidadania, educação, saúde"; "o meio ambiente somos nós que fazemos"; "se faz política acreditando nos outros"; "aprendendo a interpretar uma opinião"[motivos do falante]; "os novos discutem mais, até a própria lei; o pessoal está pensando mais; vai levar um tempo mas vai mudar"; "movimentos sociais conseguem mudar pela força do número"; "visão mais ampla, "bola de neve' do PT"; "projeto coletivo: satisfação muito grande"; "orçamento participativo do governo por si só não funciona"; "programação subterrânea que não se vê, mas sabe-se que existe"; "OP: é por aí, mas com iniciativa própria".

14 Para não sobrecarregar o texto com tabelas, salientamos apenas que os resultados apresentados a seguir, resultam da aplicação dos testes estatísticos "Qui-quadrado" e de "resíduos ajustados".

15 Ver críticas, nesta direção, de Kaase et al. (1999, Introduction) de que "(Our...) findings support the argument that much of the shift from materialist to postmaterialist values by the Euro-Barometer since the early 1980 s is a measurement artifact".

16 Nas entrevistas que tivemos em Porto Alegre com os responsáveis pela educação pública naquela cidade constatamos a importância das políticas de reforma curricular, e outras iniciativas do poder público, para assegurar as mudanças no processo de socialização, nos períodos da infância e adolescência. Estas iniciativas decorrem do impacto que constatamos nesta pesquisa, de uma nova cultura política existente no eleitorado daquela cidade - tentando assegurar a sua continuidade e desdobramento, no civismo das novas gerações.

17 Habermas (1979) notou as relações com a tradição que permitem a consolidação da mudança cultural, quando se entende essa mudança “(...) como processos de aprendizagem, através dos quais as estruturas de racionalidade já latentes podem ser traduzidas em prática social, de modo a encontrar finalmente uma corporificação institucional, colocandose a ulterior tarefa de identificar o potencial de racionalização das tradições" (p. 39 da tradução brasileira). 
Abstract: Political culture in Porto Alegre and Curitiba: Democracy, modernization and the content of public reason.

This is a comparative study of certain basic characteristics of political culture in the cities of Curitiba and Porto Alegre, analizing their diversity and convergence as local complementary forms of the constitution of citizenship. These differences are related to their sociohistorical context during the processes of democratization of the public sphere. This work argues against the usual deterministic bias and over-generalization procedures of conventional empirical studies of political culture oriented by modernization theories. The present study argues for an approach that portrays and interprets the pluralistic constitution of political culture expressed through the exercise of citizenship during the processes of democratization.

Key-words: modernization, democratization, political culture and subcultures, citizenship, socio-historical contexts, pluralism.

\section{Referências bibliográficas}

ALEXANDRE, Agripa Faria. Ambientalismo político, seletivo e diferencial no Brasil. 2003. Tese (Doutorado) - Programa de Pós-Graduação Interdisciplinar em Ciências Humanas, UFSC.

ANDRADE, Regis. The Economics of underdevelopment, the State and Politics in ECLA's doctrine. Occasional Papers, University of Glasgow, n. 29, 2003.

BERMEO, Nancy. Democracy and the lessons of dictatorship. Comparative Politics, n. 24, p. 273-291, April, 1992.

BROWN, Robert; CARMINES, Edward. Materialists, postmaterialists, and the criteria for political choice in U.S. presidential elections. Journal of Politics, n. 57, p. 483-494, 1995.

CHILTON, Stephen. Grounding political development. Boulder: Lynne Rienner, 1990.

CLARK, Terry Nichols; INGLEHART, Ronald. The new political culture: changings dynamics of support for the welfare state and other policies in post-industrial societies. In: ISA CONGRESS. Madrid, July 14, 1990. 
CLARKE, Harold. Refutations affirmed: conversations concerning the eurobarometer values battery. Political Research Quarterly, Sept. 2000.

CLIQUET, R. L. The second demographic transition: fact or fiction? Strasbourg: Council of Europe, 1991.

CONOVER, Pamela J.; SEARING, Donald D. Democracy, citizenship and the study of political socialization. In: BUDGE, Ian; MCKAY, David. Developing Democracy, London: Sage Publications, 1995.

COSTA, Sergio. Contextos de construção do espaço público no Brasil. Novos Estudos CEBRAP, n. 47, 1997.

DAVIS, Darren W.; DAVENPORT, Christian. Assessing the validity of the postmaterialism index. American Political Science Review, n. 93, p. 905-920, Sept. 1999.

DEGRAAF, N. D.; EVANS, G. Why are the young more post-materialist? A cross-national analysis of individual and contextual influence on post-material values. Comparative Political Studies, n. 28, p. 608$653,1996$.

DIAMOND, Larry. Economic development and democracy reconsidered. In: MARKS, Gary; DIAMOND, Larry (Orgs.). Reexaminig democracy: essays in honor of Seymour Martin Lipset. Newbury Park: Sage Publications, 1991.

DIAS, Marcia Ribeiro. Voto e participação política: o impacto do orçamento participativo sobre o comportamento eleitoral em Porto Alegre. 2003. (CNPq - Projeto de Produtividade em Pesquisa).

ECHEGARAY, Fabián; KRISCHKE, Paulo; TOSO, Aluir. Clivagens geracionais nos valores sócio-políticos: o caso do Brasil. Revista de Ciências Humanas, v. 16, n. 23, p. 35-46, 1998.

ECHEGARAY, Fabián; ARMENTO, Michel. Quão ecologista devo ser se eu for um pós-materialista? In: KRISCHKE, Paulo (Org.). Ecologia, juventude e cultura política. Florianópolis: Ed. da UFSC, 2000.

ESCOBAR, Arturo. Reflections on 'development': grassroots approaches and alternative politics in the Third World. Futures, p. 411-436, June, 1992.

GEDDES, Barbara. The politics of economic liberalization. Latin American Research Review, v. 30, n. 2, p. 195-215, 1995. 
HABERMAS, Jürgen. Communication and the evolution of society. Boston: Beacon Press, 1979.

Consciência moral e agir comunicativo. Rio de Janeiro: Tempo Brasileiro, 1989.

HALLER, Max. Theory and method in the comparative study of values: critique and alternative to Inglehart. European Sociological Review, v. 18, n. 2, p. 139-158, 2002.

INGLEHART, Ronald. Modernization and Postmodernization: cultural, economic and political change in 43 societies. New Jersey: Princeton University Press, 1997.

KAASE, Max et al. The effect of economic priorities on the measurement of value change: new experimental evidence. American Political Science Review, Sept. 1999.

KRISCHKE, Paulo J. Escolha racional e cultura política: interfaces nos estudos da democratização na América Latina. BIB, Revista Brasileira de Informação Bibliográfica, n. 43, p. 103-126, 1997.

. Juventude e socialização no Sul do Brasil. In: KRISCHKE, P. (Org.). Ecologia, juventude e cultura política. Florianópolis: Ed. da UFSC, 2000.

Aprender a democracia na América Latina: notas sobre o aprendizado político e as teorias da democratização. In: LEIS, Hector; SCHERER-WARREN, Ilse; COSTA, Sérgio (Orgs.). Modernidade crítica e modernidade acrítica. Florianópolis: Cidade Futura, 2001.

Aprendendo a democracia na América Latina. Porto Alegre: Ed. da PUCRS, 2003.

Cultura política: convergências e diferenças em Porto Alegre e Curitiba. Revista de Ciências Humanas, n. 35, p. 141-176, 2004.

JOHNSON, Chalmers. Revolutionary change. Boston: Little, Brown and Co., 1966.

LIPSET, Seymour Martin. Political man. New York: Doubleday, 1960.

LIPSET, Seymour Martin; KYUONG-RYUNG Seong; TORRES, John Charles. A comparative analysis of the social requisites of democracy. International Social Science Journal, n. 136, p. 155-75, May, 1993.

LINDENBERG, S. Homo socio-oeconomicus: the emergence of a general model of man in the Social Sciences. Journal of Institutional and Theoretical Economics, v. 14, n. 4, 1990. 
MARSHALL, G. Repositioning class: social inequality in industrial societies. London: Sage Publications, 1997.

MUNCK, Gerardo. Disaggregating political regime: conceptual issues in the study of democratization. Kellogg Working Papers, n. 228, 1996.

PARSONS, Talcott. The social system. New York: Free Press, 1951.

PRZEWORSKI, Adam; LIMONGI, Fernando. Democracy and development in South America, 1946-1988. Washington, DC: APSA, 1993.

QUINTAL, Fátima. Significados atribuídos às frases da bateria de Inglehart: relatório técnico ao CNPq. 2001

RAHN, W.; TRANSUE, J. Social trust and value change: the decline of social capital in American youth. Political Psychology, v. 19, n. 3, p. 545-565, 1998.

RAWLS, John. Political Liberalism. New York: Columbia University Press, 1993.

REMMER, Karen L. Democracy and economic crisis. World Politics, v. 42, n. 3, p. 315-35, 1990.

SOMERS, Margareth R. Narrating and naturalizing citizenship theory: the place of political culture and the public sphere. Sociological Theory, v. 13, n. 3, p. 229-274, 1995.

STOLLE, D.; HOOGHE, M. Preparing for the learning school of democracy: the effects of youth and adolescent involvement on value patterns and participation in adult life. Paper presented at ECPR Joint Sessions, Turin, 22-27 March, 2002. Disponível em: http://essex.ac.uk/ecpr/ events/jointsessions/paperarchive/turin/ws7/StolleHooghe.pfg>.

TRANTER, Bruce; WESTERN, Mark. Postmaterialism and age: an Australian anomaly? In: CONFERENCE OFTHEAUSTRALASIAN POLITICAL STUDIES ASSOCIATION, Canberra, October, 2002. 
